\title{
In vitro Antimycobacterial Activity of Selected Medicinal Plants against Mycobacterium tuberculosis
}

\author{
Kpatcha E. Poro ${ }^{1}$, Yao Hoekou ${ }^{1 *}$, Passimna Pissang ${ }^{1}$, Iwaba Kpabi ${ }^{1}$, Kosi M. Novidzro ${ }^{2}$, \\ Anoumou Y. Dagnra ${ }^{3}$, Tchadjobo Tchacondo ${ }^{1}$ and Komlan Batawila ${ }^{4}$
}

${ }^{1}$ Laboratoire des Sciences Biomédicales, Alimentaires et de Santé Environnementale

(LaSBASE). Ecole Supérieure des Techniques Biologiques et Alimentaires (ESTBA),

Université de Lomé, Togo

${ }^{2}$ Laboratoire de Génie des Procédés et des Ressources Naturelles (LAGEPREN). Faculté des

Sciences (FDS), Université de Lomé, Togo

${ }^{3}$ Laboratoire National de Référence des Mycobactéries au Togo (LRM), Centre Hospitalier

Universitaire Sylvanus Olympio (CHU-SO), Lomé, Togo

${ }^{4}$ Laboratoire de Botanique et Ecologie Végétale, Faculté des Sciences (FDS), Université de

Lomé, Togo

*Corresponding author

\section{A B S T R A C T}

\section{Keywords}

Medicinal plants, Antimycobacteriala ctivity, MABA, MIC, $M$. tuberculosis, Togo

Article Info

Accepted:

22 January 2021

Available Online:

10 February 2021
The objective of this study was to evaluate the antimycobacterial activity of Carissa edulis, Sarcocephalus latifolius, and Vitex doniana, three Togolese medicinal plants, used locally for the management of tuberculosis (TB) against Mycobacterium tuberculosis. Hydroethanolic extracts of the roots of C.edulis and S.latifolius, and leaves of V.doniana were obtained by maceration. The in vitro antimycobacterial activity was evaluated using Microplate Alamar Blue Assay (MABA). The phytochemical screening of the extracts was performed on the basis of tests for coloring characteristics to identify the major chemical groups. The hydroethanolic extracts of the leaves of $V$. doniana and roots of $C$. edulisand $S$. latifolius had antimycobacterial activity against $M$. tuberculosis with minimum inhibitory concentration (MIC) ranging from 312.5-1,250 $\mu \mathrm{g} / \mathrm{mL}$. The best MIC was obtained for the leaves of $V$. doniana. The extracts of the three plants contain alkaloids, flavonoids, tannins, saponins, and cardiac glycosides except the saponins which are absent in the root of $C$. edulis. The present study supports the local use of these plants in the management of TB. However, further investigations are needed on isolating and identifying chemical constituents responsible for the observed activity, and also on the toxicity of these plants.

\section{Introduction}

Tuberculosis (TB) is a communicable disease that is a major cause of ill health, one of the top 10 causes of death worldwide and the leading cause of death from a single infectious agent. TB is caused by the bacillus Mycobacterium tuberculosis, which is spread 
when people who are sick with TB expel bacteria into the air; for example, by coughing. The disease typically affects the lungs (pulmonary TB) but can also affect other sites (extrapulmonary TB). About a quarter of the world's population isinfected with M. tuberculosis (WHO, 2020; Brudey et al., 2006).Globally, in 2019, an estimated 10.0 million people fell ill with TB, a number that has been declining very slowly in recent years. There were an estimated 1.2 million TB deaths among HIV-negative people in 2019, and an additional 208000 deaths among HIVpositive people (WHO, 2020).

Moreover, drug-resistant TB continues to be a public health threat. Worldwide in 2019, close to half a million people developed rifampicinresistant $\mathrm{TB}$, of which $78 \%$ had multidrugresistant TB. The increase in the incidence of clinical tuberculosis is associated with increasing reports of new cases of multidrugresistant (MDR-TB) and extensively multi drug-resistant (XDR-TB) strains (Brudey et al., 2006). Management of TB/MDR-TB patient requires intense multi-chemotherapy for at least six months to two years. It is very hurtful to a patient's health due to high levels of drug toxicity and its adverse effects (Rivoire et al., 2007; Aleme and Gebeyehu, 2010; Hannan et al., 2011). Faced with this situation, the development of new drugs is critical for the future control of tuberculosis. Natural products, either as pure compounds or as standardized plant extracts, provide unlimited opportunities for new drug leads because of the unmatched availability of chemical diversity (Hamisi et al., 2009). It is with this in mind that work has focused on plants used in the treatment of several diseases including tuberculosis (Madikizela et al., 2017). Several plants have been identified in the treatment of tuberculosis and other diseases caused by mycobacteria (Madikizela et al., 2017; Makagni et al., 2020). Moreover, higher plant extracts have been considered as promising sources of novelanti-TB leads (Mitscher and Baker, 1998; Kahaliw et al., 2017). This has prompted us to investigate Carissa edulis Vahl (Apocynaceae), Sarcocephalus latifoliu (Sm.) E.A. Bruce (Rubiaceae) and Vitex doniana Sweet (Lamiaceae), three medicinal plants used in Togo in the management of TB, for possible anti-TB activities. So, the objective of the present study is to evaluate the in vitro antimycobacterial activity of hydroalcoholic extracts of these three plants on Mycobacterium tuberculosis and then to carry out the phytochemical screening of the tested extracts.

\section{Materials and Methods}

\section{Collection of plants materials}

The roots of Carissa edulisand Sarcocepha luslatifolius, and leaves of Vitex doniana, were collected from Pagala Gare (Blitta district of Togo) in March 2019. The plants materials were botanically authenticated atthe Herbarium of Botanical Department, Faculty of Sciences, University of Lomé.

\section{Preparation of the extract}

The extraction was performed according to Hoekou et al., (2017). The samples of each plant were washed thoroughly under running tap water, and dried in air at room temperature for two weeks. After wards, the plant materials were powdered using a grinding machine. The ethanolic extraction was performed by maceration of $100 \mathrm{~g}$ powder in $1,000 \mathrm{~mL}$ of $70 \%(\mathrm{v} / \mathrm{v})$ ethanol, under continuous stirring for 48 hours at room temperature. The extract was filtered through Whatman No.1 filter paper and evaporated at $45^{\circ} \mathrm{C}$ using a rotary evaporator to dryness under reduced pressure. The extracts were preserved at $4{ }^{\circ} \mathrm{C}$ in refrigerator till used. 


\section{In vitro antimycobacterial assay}

\section{Bacterial strains}

The microorganisms used for the test were clinical strains of Mycobacterium tuberculosis isolated from the National Tuberculosis Reference Laboratory of the University Hospital Centre Sylvanus Olympio (CHU$\mathrm{SO})$ of Lomé.

\section{Microplate alamar blue assay (MABA)}

Mycobacterial strains were freshly subcultured on Lowenstein-Jensen (LJ) medium. The inoculum was prepared from a BD BACTEC Mycobacterial Growth Indicator Tube (MGIT) $7 \mathrm{~mL}$ positive tube within 5 days. Mix the contents of the tube well by vortexing it, then dilute it to $1 / 5$ by adding $1 \mathrm{~mL}$ of culture to $4 \mathrm{~mL}$ of sterile sodium chloride $(0.9 \%)$ and mix well (solution A). Add $0.1 \mathrm{~mL}$ of this solution A to $9.9 \mathrm{~mL}$ of MGIT supplemented with $0.8 \mathrm{~mL}$ of sterile sodium chloride (solution B). Close tightly and mix 2-3 times by turning (BD BBL MGIT, 2016). The microplateal amarblue assay was carried out as described by Palomino et al., (2002). Briefly, $100 \mu \mathrm{L}$ of MGIT broth was dispensed in each well of a sterile flat-bottom 96-well plate, and serial two fold dilutions of the crude extracts, and isoniazid (INH) an drifampicin (RIF), as positive control drugs, were prepared directly in the plate.

One hundred microliters of inoculum was added to each well. A growth control treated with the vehicle (sterile distilled water) and a sterile control were also included for each mycobacterial strain. Sterile water was added to all perimeter wells to avoid evaporation during the incubation. The plates were covered, sealed with Parafilm, and incubated at $37{ }^{\circ} \mathrm{C}$ under a normal atmosphere. After 7 days of incubation, $32.5 \mu \mathrm{L}$ of a mixture of MGIT $(1.9225 \mathrm{~mL})$, distilled water $(3.0275$
$\mathrm{mL})$ and Resazurin $(0.05 \mathrm{~mL})$ or alamar blue solution was added to each well, and the plate was reincubated overnight. A change in color from blue to pink indicated the growth of bacteria, and the minimum inhibitory concentration (MIC) was defined as the lowest concentration of the crude extract or positive control drug that prevented this change in color. The crude extract and drug concentration ranges used were as follows: for crude extracts, 5,000 to $9.75 \mu \mathrm{g} / \mathrm{mL}$, INH, 64 to $0.12 \mu \mathrm{g} / \mathrm{mL}$ and RIF, 83 to $0.16 \mu \mathrm{g} / \mathrm{mL}$. All the experiments were carried out in triplicate.

\section{Phytochemical analysis}

Phytochemical screening was performed on the basis of tests for coloring characteristics to highlight the major chemical groups. It focused on hydroethanolic extracts of the studied plants. The chemical groups were identified by reference to the methods described by Harbone(1976).

\section{Alkaloids}

The techniques of Dragendorff and Mayer were used. Two drops of Dragendorff's reagent were added to $2 \mathrm{~mL}$ of each extract solution. A red-orange precipitate indicated a positive reaction. The appearance of white or white-yellow precipitate after addition of 2 drops of Mayer's reagent to $2 \mathrm{~mL}$ of each extract solution indicated the presence of alkaloids.

\section{Flavonoids}

In a tube containing $2 \mathrm{~mL}$ of extract, a few drops of $10 \% \mathrm{NaOH}$ were added. Appearance of yellow-orange color indicated the presence of flavonoids. In the second method, two drops of ferricchloride $(\mathrm{FeCl} 3)$ were added to $2 \mathrm{~mL}$ of extract. Appearance of greenish color reveals the presence of flavonoids. 


\section{Saponins}

Samples $(0.1 \mathrm{~g}$ of dry extract) were dissolved in $10 \mathrm{~mL}$ of distilled water. The samples were shaken vigorously up and down for 30-45 seconds and then left for 15 minutes.

The height of the foam was measured. Persistent foam for more than $1 \mathrm{~cm}$ high indicated the presence of saponins.

\section{Tannins}

Two milliliters of water and few drops of $1 \%$ ferricchloride were added to $1 \mathrm{~mL}$ of extract. The appearance of a blue, blue-black or black coloration indicated the presence of gallic tannins, the green or dark green coloration showed the presence of catechic tannins.

\section{Cardiac glycosides}

Two milliliters of chloroform were added to 1 $\mathrm{mL}$ of each extract solution. The appearance of a reddish-brown coloration after addition of $1 \mathrm{~mL}$ concentrated sulphuricacid revealed the presence of cardiac glycosides.

\section{Results and Discussion}

\section{Antimycobacterial activity}

In the present study, the in vitro antimycobacterial activity of the roots of Carissa edulis and Sarcocepha luslatifolius, and the leaves of Vitex doniana was examined against clinical pathogenic strains of Mycobacterium tuberculosis. The extracts were evaluated in a concentration series of 5,000 to $9.75 \mu \mathrm{g} / \mathrm{mL}$, while isoniazid and rifampicin respectively with 64 to $0.12 \mu \mathrm{g} / \mathrm{mL}$ and 83 to $0.16 \mu \mathrm{g} / \mathrm{mL}$ concentrations. The wells were pink below a concentration of $1,250 \mu \mathrm{g} / \mathrm{mL}$ for the extract of C. edulis, 625 $\mu \mathrm{g} / \mathrm{mL}$ for the extract of S. latifolus and 312.5 $\mu \mathrm{g} / \mathrm{mL}$ for $V$. doniana extracts. For isoniazid and rifampicin, the microtiter wells were pink respectively below a concentration of 2 $\mu \mathrm{g} / \mathrm{mL}$ and $5.2 \mu \mathrm{g} / \mathrm{mL}$. All well streated with sterile distilled water (the vehicle) were pink, demonstrating no inhibitory role of the vehicle, by contrast, for sterile control, the wells were blue (Table 1). These observations allow us to determine the minimum inhibitory concentrations of the extracts and positive control drugs presented in Table 2.

Table.1 Colors obtained for test suspension in the wells after reincubation

\begin{tabular}{|c|l|l|l|l|l|l|l|l|l|l|l|}
\hline \multirow{2}{*}{ RECE } & Conc $(\boldsymbol{\mu g} / \mathbf{m L})$ & $\mathbf{5 , 0 0 0}$ & $\mathbf{2 , 5 0 0}$ & $\mathbf{1 , 2 5 0}$ & $\mathbf{6 2 5}$ & $\mathbf{3 1 2 . 5}$ & $\mathbf{1 5 6}$ & $\mathbf{7 8}$ & $\mathbf{3 9}$ & $\mathbf{1 9 . 5}$ & $\mathbf{9 . 7 5}$ \\
\cline { 2 - 12 } & Color & blue & blue & blue & pink & pink & pink & pink & pink & pink & pink \\
\hline \multirow{3}{*}{ RESL } & Conc $(\mu \mathrm{g} / \mathrm{mL})$ & 5,000 & 2,500 & 1,250 & 625 & 312.5 & 156 & 78 & 39 & 19.5 & 9.75 \\
\cline { 2 - 11 } & Color & blue & blue & blue & blue & pink & pink & pink & pink & pink & pink \\
\hline \multirow{3}{*}{ LEVD } & Conc $(\mu \mathrm{g} / \mathrm{mL})$ & 5,000 & 2,500 & 1,250 & 625 & 312.5 & 156 & 78 & 39 & 19.5 & 9.75 \\
\cline { 2 - 11 } & Color & blue & blue & blue & blue & blue & pink & pink & pink & pink & pink \\
\hline \multirow{2}{*}{ INH } & Conc $(\mu \mathrm{g} / \mathrm{mL})$ & 64 & 32 & 16 & 8 & 4 & 2 & 1 & 0.5 & 0.25 & 0.12 \\
\cline { 2 - 10 } & Color & blue & blue & blue & blue & blue & blue & pink & pink & pink & pink \\
\hline \multirow{2}{*}{ RIF } & Conc $(\mu \mathrm{g} / \mathrm{mL})$ & 83 & 41.5 & 20.8 & 10.4 & 5.2 & 2.6 & 1.3 & 0.65 & 0.32 & 0.16 \\
\hline & Color & blue & blue & blue & blue & blue & pink & pink & pink & pink & pink \\
\hline GC+ SDW & Color & pink & pink & pink & pink & pink & pink & pink & pink & pink & pink \\
\hline Sterilecontrol & Color & blue & blue & blue & blue & blue & blue & blue & blue & blue & blue \\
\hline
\end{tabular}

RECE $=$ Root extract of C. edulis, RESL $=$ Root extract of S. latifolius, LEVD = Leavesextract of V. doniana, INH

$=$ isoniazid, $\mathrm{RIF}=$ rifampicin, $\mathrm{GC}+\mathrm{SDW}=$ Growth control treatedwithsteriledistilled water Conc $=$ concentrations 
Table.2 Minimum inhibitory concentration (MIC in $\mu \mathrm{g} / \mathrm{mL}$ ) values of hydro-ethanolic extracts of tested medicinal plants

\begin{tabular}{|l|l|l|}
\hline Plant species & Part used & CMI \\
\hline Carissa edulis & Roots & 1,250 \\
\hline Vitex doniana & Leaves & 312.5 \\
\hline Sarcocepha luslatifolius & Roots & 625 \\
\hline Isoniazid (INH) & - & 2 \\
\hline Rifampicin (RIF) & - & 5.2 \\
\hline
\end{tabular}

Table.3 Phytochemical composition of the tested extracts

\begin{tabular}{|l|c|c|c|c|c|}
\hline Plant extracts & Saponins & Alkaloids & Flavonoids & Tannins & $\begin{array}{c}\text { Cardiac } \\
\text { glycosides }\end{array}$ \\
\hline Carissa edulis & - & + & + & + & + \\
\hline $\begin{array}{l}\text { Sarcocepha } \\
\text { luslatifolius }\end{array}$ & + & + & + & + & + \\
\hline Vitex doniana & + & + & + & + & + \\
\hline
\end{tabular}

The leaves from $V$. doniana displayed the best in vitro activity against the mycobacterial strains tested. The MIC were $312.5 \mu \mathrm{g} / \mathrm{mL}$ for $V$. doniana, $625 \mu \mathrm{g} / \mathrm{mL}$ for S. latifolius, and $1,250 \mu \mathrm{g} / \mathrm{mL}$ for $C$. edulis. Under these same experimental conditions isoniazid (INH) and rifampicin (RIF) gave respectively minimal inhibitory concentrations of $2 \mu \mathrm{g} / \mathrm{mL}$ and 5.2 $\mu \mathrm{g} / \mathrm{mL}$ (Table 2).

\section{Phytochemicals}

The results of the phytochemicals screening are recorded in Table 3. The presence of alkaloids, flavonoids, tannins, saponins, and cardiac glycosides is revealed in the tested extracts except saponins which are absent in Carissa edulis roots extract.

Current TB therapy consists of treatment with a combination of drugs. This combination therapy causes hepatotoxicity as the major side effect as well as development of drug resistance (Kahaliw et al., 2017). Using medicinal plants for the treatment of TB offers a great hope to fulfill these needs because of their chemical diversity and they have been used for curing diseases for many centuries (Lawal et al., 2011). In addition, natural herbs continue to play a great significant role in the drug discovery and development of highly active antimycobacterial metabolites and they can be used as pure compounds or as crude materials (Guzman et al., 2010). In this study, the inhibitory activity of extracts on Mycobacterium tuberculosis was evaluated using the "Microplate Alamar Blue Assay (MABA) study protocol. Crude hydroethanolic extracts of all the three plants tested for their antimycobacterial activity against $M$. tuberculosis strains by using MABA had showed antimycobacterial activity with the mean MIC values ranging from 312.5 to $1,250 \mu \mathrm{g} / \mathrm{mL}$. According to Kuete (2010), a crude extract is considered to have antimicrobial activity during a susceptibility test if its minimum inhibitory concentration (MIC) is in the range of 100$1,000 \mu \mathrm{g} / \mathrm{mL}$.

The activity is significant when the MIC is less than $100 \mu \mathrm{g} / \mathrm{mL}$, moderate when the MIC is between $100-625 \mu \mathrm{g} / \mathrm{mL}$ and low when 
the MIC is higher than $625 \mu \mathrm{g} / \mathrm{mL}$. Therefore, $V$. doniana leaves and $S$. latifolius extracts have moderate activity on mycobacterial growth while it is low for extracts from Carissa edulis roots. The antimycobacterial activity of the plants tested is very little studied. The study of Kahaliw et al., (2017) has shown that the chloroform extract of the root of $C$. edulis is inactive on the $M$. tuberculosis H37Rv strain. But, the antimicrobial activity of the extracts of $C$. edulis has been demonstrated against Escherichia coli and Staphylococcus aureus (Abdu et al., 2008). No report was found during a literature search against Mycobacterium strains apart from ethnobotanical reports on $S$. latifolius and $V$. doniana. Therefore, this investigation would be the first report on their antimycobacterial activities. As for S. latifolius, its extracts of stem bark and leaves have been tested for their antimicrobial activity while the activity of its root has not yet been elucidated (Djeussi et al., 2016). Other studies have shown that extracts of $V$. doniana possess antimicrobial activities against $E$. coli, multidrug resistant B. cepacia and $P$. aeruginosa, methicillinresistant $S$. aureus, and vancomycin-resistant Enterococcus (Taiwo et al., 2009; Nwachukwu and Uzoeto, 2010). Studies have reported several pharmacological properties of these tested plants confirming their usefulness in traditional medicine (Amégbor et al., 2012; Ogbole et al., 2018; Mailu et al., 2020).

The phytochemical study on the three plants showed the presence of alkaloids, flavonoids, tannins, saponins, and cardiac glycosides except the saponins which are absent in the extract of C. edulis. C. edulis extract does not contain saponins and is the one which gave the low activity among the extracts tested. This lets us say that the saponins may have played a role in the antimycobacterial activity of the extracts tested. Previous studies have reported that antimycobacterial activity against $M$. tuberculosis maybe due to the bioactive constituents, such as flavonoids, saponins, tannins, alkaloids, phenols, and others (Arya, 2011; McCarthy and Mahony, 2011).

This report agrees with the previous of other authors who also found that the extracts of $V$. doniana, C. edulis and S. latifolius contain flavonoids, saponins, tannins, alkaloids, and others (Deleke Koko et al., 2011; James et al., 2014; Kaunda and Zhang, 2017).

In conclusion the hydroethanolic extracts from the leaves of $V$. doniana and roots of $S$. latifolius and $C$. edulis inhibited in vitrothe growth of Mycobacterium tuberculosis and contain chemical constituents responsible for antimicrobial activities. The overall results of the present study provides baseline information for the possible use of the tested plants, especially $V$. doniana and S. latifolius in the control of infections due to Mycobacterium tuberculosis. But, these plants should be fractionated to obtain the most fractions with promising antimycobacterial activity and then, to conclude their antituberculosis activity. In addition, further investigations should focus on isolating and identifying chemical constituents responsible for anti-TB activities observed in these plants and also elucidating the toxicity of the tested plants.

\section{References}

Abdu, K. B., Khan, M. E., and Rumah, M. M. 2008. Antimicrobial activity and phytochemical screening of extractsfrom the root bark of Carissa edulis, against human/animal pathogens. Cont $\mathrm{J}$ Trop Med. 2: 1 .

Aleme, G. A., and Gebeyehu, A. 2010. Clinical Improvement and Drug-adverse Effects among Patients Taking Anti-tuberculosis Drugs. Ethiopian Journal of Health and 
Biomedical Sciences. 2 : 103-110.

Amégbor, K., Metowogo, K., Eklu-Gadegbeku, K., Agbonon, A., Aklikokou, K. A., Napo-Koura G., and Gbeassor M. 2012. Preliminary evaluation of the woundhealingefect of Vitex donianasweet (Verbenaceae) in mice. Afr $\mathrm{J}$ TraditComplementAltern Med. 9 : 58490.

Arya, V. 2011. A Review on Anti-Tubercular Plants. Int J Phar Tech Res. 3: 872-880.

BD BBL MGIT. 2016. Tube avec indicateur de croissance mycobactérienne $7 \mathrm{~mL}$ avec le coffret du supplément BD BACTEC MGIT 960. Pour le test de sensibilité de Mycobacterium tuberculosis aux antimycobactériens. 5-8. Accessed 26 Oct 2018.

Brudey, K., Driscoll, J. R., and Rigouts, L. 2006. Mycobacterium Tuberculosis complex genetic diversity: mining the fourth international spoligotyping database (SpolDB4) for classification. BMC Microbiol. 6: 23.

Deleke Koko, I. K. E., Djego, J., Gbenou, J., Hounzangbe-Adote, S. M., and Sinsin, B. 2011. Etude phytochimique des principales plantes galactogènes et emménagogues utilisées dans les terroirs riverains de la Zone cynégétique de la Pendjari. Int. J. Biol. Chem. Sci. 5(2): 618-633.

Djeussi, D. E., Noumedem, J. A. K., Ngadjui, B. T., and Kuete, V. 2016. Antibacterial and antibiotic-modulation activity of six Cameroonian medicinal plants against Gram-negative multi-drugresistant phenotypes. BMC Complementary and Alternative Medicine. $16: 124$.

Guzman, J. D., Gupta, A., Evangelopoulos, D., Basavannacharya, C., Pabon, L. C., Plazas, E. A., Muñoz, D. R., Delgado, W. A., Cuca, L. E., Ribon, W., Gibbons, S., and Bhakta S. 2010. Anti-tubercular Screening of Natural Products from Colombian Plants: 3 Methoxynor domesticine, an Inhibitor of MurE Ligase of Mycobacterium tuberculosis. J Antimicrob Chemother. 65: 2101-2107.
Hamisi, M. M., Vitus, A. N., and Andrew, M. 2009. Anti-TB Natural Products in Tanzanian Medicinal Plants. http://www.nimr.or.tz/ Anti-TB Natural Products in Tanzanian Medicinal Plants. Accessed 31 Oct 2018.

Hannan, A., Ullah, M. I., Usman, M., Hussain, S., Absar, M., and Javed, K. 2011. Antimycobacterial activity of Garlic (Allium sativum) against Multi-drug resistant and non-Multi-drug resistant Mycobacterium tuberculosis. Pakistan Journal of Pharmaceutical Science. 24: $81-85$.

Harbone, J. B. 1976. Phytochemical Methods. A Guide to Modern Techniques of Plant Analyses. Chapman and hall: London.

Hoekou, Y. P., Tchacondo, T., Karou, D. S., Yerbanga, R. S., Achoribo, E., Da, O., Atakpama, W., and Batawila, K. 2017. Therapeutic potentials of ethanolic extract of leaves of Holarrhena floribunda (G. Don) Dur. and Schinz (Apocynaceae). Afr J Tradit Complement Altern Med. 14(2): 227-233.

James, D. B., Sheneni, V. D., Kadejo, O. A., Yatai, K. B. 2014. Phytochemical screening and in vitro antioxidant activities in different solvent extracts of Vitex doniana leaves, stem bark and root bark. Am. J. Biomed \& Life Sciences. 2(1) : 22-27.

Kahaliw, W., Aseffa, A., Abebe, M., Teferi, M., and Engidawork, E. 2017. Evaluation of the antimycobacterial activity of crude extracts and solvent fractions of selected Ethiopian medicinal plants. BMC Complementary and Alternative Medicine. 17(143). DOI 10.1186/s12906017-1563-0.

Kaunda, J. S., and Zhang, Y-J. 2017. The Genus Carissa: An Ethnopharmacological, Phytochemical and Pharmacological Review. Nat. Prod. Bioprospect. 7: 181199.

Kuete, V. 2010. Potential of Cameroonian plants and derived products against microbial infections: A review. Planta 
Medica. 76 : 1479-1491.

Lawal, T. O., Adeniyi, B., Wan, A. B., Franzblau, S. G., and Mahady, G. B. 2011. In VitroSusceptibility of Mycobacterium tuberculosis to Extracts of Uvaria afzelli Scott Elliot and Tetracera alnifolia Willd. Afr J Biomed Res. 14: 17-21.

Madikizela, B., Kambizi, L., and McGaw, L.J. 2017. An ethnobotanical survey of plants usedtraditionally to treattuberculosis in the easternregion of O.R. Tambo district, South Africa. South African Journal of Botany. 109: 231-236.

Makagni,T. K., Gbekley, E. H., Hoekou, Y., Maman, I., Pissang, P., Agbodeka, K., Tchacondo, T., Karou, D. S., and Batawila, K. 2020. Ethnobotanical study of medicinal plants in the fight against buruli ulcer in the Maritime Region of Togo. European Scientific Journal. 16(27): 239-255.

Mailu, J. K., Nguta, M. J., Mbaria, M. J., and Okumu, O. M. 2020. Medicinal plants used in managing diseases of the respiratory system among the Luo community: an appraisal of Kisumu East Sub-County, Kenya. BMC Chinese Medicine. 15: 95.

McCarthy, E., and Mahony, M. O. 2011. What's in a Name? Can Mullein Weed Beat TB Where Modern Drugs Are Failing? Evid-Based Complement and Altern Med. 2011: 1-7.

Mitscher, L. A. and Baker, W. R. 1998. A search for novel chemotherapy against tuberculosis amongst natural products.
Pure ApplChem. 70(2) : 365-271.

Nwachukwu, E., and Uzoeto, H. O. 2010. Antimicrobial activities of leaf of Vitex doniana and Cajanus cajan on some bacteria. Researcher. 2 : 37-47.

Ogbole, O. O., Akinleye, T. E., Segun, P. A., Faleye, T. C., and Adeniji, A. J. 2018. In vitro antiviral activity of twenty-seven medicinal plant extractsfrom Southwest Nigeria against three serotypes of echoviruses. BMC Virology Journal. 15: 110.

Palomino, J-C., Martin, A., Camacho, M. Guerra, H., Swings, J., and Portaels, P. 2002. Resazurin Microtiter Assay Plate: Simple and Inexpensive Method for Detection of Drug Resistance in Mycobacterium tuberculosis. Antimicrobial Agents and Chemotherapy. 46(8): 2720-2722.

Rivoire, N., Ravololonandriana, P., Rasolonavalona, T., Martin, A., Portaels, F., Ramarokoto, H., Rasolofo Razanamparany, V. 2007. Evaluation of the Resazurin Assay for the Detection of Multidrug-resistant Mycobacterium tuberculosis in Madagascar. International Journal of Tuberculosis and Lung Disease. 11 (6): 683-688.

Taiwo, O., Xu, H., and Lee, S. 1999. Antibacterial activities of extracts from Nigerian chewing sticks. PhytotherRes. 13: 675-9.

WHO. 2020. Global tuberculosis report 2020. Geneva: World Health Organization; 2020. Licence: CC BY-NC-SA 3.0 IGO.

\section{How to cite this article:}

Kpatcha E. Poro, Yao Hoekou, Passimna Pissang, IwabaKpabi, Kosi M. Novidzro, Anoumou Y. Dagnra, Tchadjobo Tchacondo and Komlan Batawila. 2021. In vitro Antimycobacterial Activity of Selected Medicinal Plants against Mycobacterium tuberculosis. Int.J.Curr.Microbiol.App.Sci. 10(02): 3201-3208. doi: https://doi.org/10.20546/ijcmas.2021.1002.351 